\title{
Xrd, Quantum Chemical, Vibrational, Thermal and Antifungal Activity Analysis on 3-Nitroanilinium Hydrogen Oxalate
}

\author{
S. Thangarasu, V. Siva, S. Athimoolam, S. Asath Bahadur
}

\begin{abstract}
: 3-nitroanilinium hydrogen oxalate has been crystallized successfully by solvent evaporation method. Optimized molecular geometrical parameters and the vibrational assignments of 3NAOX has been calculated by using Hartree-Fock (HF) and density functional method (B3LYP) with 6-311++G $(d, p)$ basis set. The computational analysis showed good agreement with the experimental data. The energy and various parameters were obtained by HOMO-LUMO plot. The apparent pharmaceutical/biological activity of the salt confirmed by lower band gap value obtain from the Frontier Molecular Orbital (FMO) analysis. Thermal properties of $3 N A O X$ were analyzed by TGA/DTA. The grown crystals were involved in an antimicrobial activity against certain potentially threatening microbes which shows that grown crystal screened the bacteria.
\end{abstract}

Keywords: 3-Nitroaniline, Quantum chemical analysis, HOMO-LUMO, Antifungal activity.

\section{INTRODUCTION}

Thein heintramolecular charge transfer from the $-\mathrm{NH}_{2}$ (electron-donor group) to $-\mathrm{NO} 2$ (electron-acceptor group) through the phenyl ring in nitroaniline, called as push-pull molecules. Optical nonlinearity by using experimental and computational method on 3-Nitroaniline and 4-nitroaniline as reference compounds [1-3]. Biologically important compounds, such as 3-Nitroaniline and its derivatives are owing to produced significant antihyperglycemic as well as hypoglycemic effects in alloxan-induced and normal diabetic rabbits [4]. Also 3-Nitroaniline plays an essential role in several biological processes and has considerable chemical and pharmacological importance

A new family of organic-inorganic crystals is proposed

Revised Manuscript Received on December 15, 2019

* Correspondence Author

S. Thangarasu*, Department of Physics, Kalasalingam Academy of Research and Education, Krishnankoil-626 126, India and Condensed Matter Physics Laboratory, International Research Centre, Kalasalingam Academy of Research and Education, Krishnankoil-626 126, India.

Email: sthangarasu@gmail.com

V. Siva, Department of Physics, Kalasalingam Academy of Research and Education, Krishnankoil-626 126, India, and Condensed Matter Physics Laboratory, International Research Centre, Kalasalingam Academy of Research and Education, Krishnankoil-626 126, India,

Email: vsiva33.physics@gmail.com

S. Athimoolam, Department of Physics, University College of Engineering Nagercoil, Anna University, Nagercoil- 629 004, India.

Email: athi81s@yahoo.co.in

S. Asath Bahadur*,Department of Physics, Kalasalingam Academy of Research and Education, Krishnankoil-626 126, India, and Condensed Matter Physics Laboratory, International Research Centre, Kalasalingam Academy of Research and Education, Krishnankoil-626 126, India.

Email : s_a_bahadur@yahoo.co.in with the background such as: biological importance, with physical, chemical and thermal properties through inorganic sub networks. Based on the above specifics, 3-nitroaniline was reacted with oxalic acid and 3-nitroanilinium hydrogen oxalate (3NAOX) crystals were grown. In this paper, the synthesis, crystal growth, structural, spectroscopic, thermal and antifungal analyses of $3 \mathrm{NAOX}$ is reported.

\section{EXPERIMENTAL SECTION}

3-nitroanilinium hydrogen oxalate (3NAOX) is synthesized from the AR grade 3-nitroaniline and oxalic acid obtained from Himedia fine Chemicals taken in 1:1 ratio in acetone. This solution stirred well about 1 hour to get clear solution. The title crystal was synthesized according to the scheme as shown in Fig. 1. After many attempts, the compound 3-nitroanilinium hydrogen oxalate (3NAOX) has not yielded good quality single crystal; which is not suitable for single crystal X-ray diffraction. Hence, the powder XRD study of 3 NAOX was carried out to confirm the new phase of the complex.

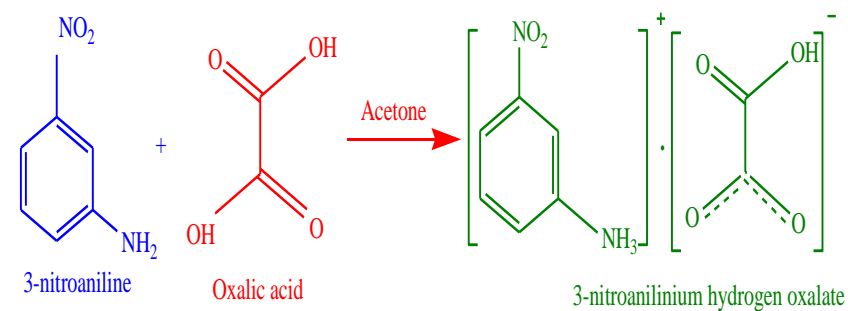

Fig. 1. Chemical Scheme of 3NAOX

\section{A. Powder XRD analysis}

Powder XRD studies of grown crystal of 3NANO was carried out by Bruker X-ray diffractometer of D8 advanced ECO XRD system with SSD160 1D Detector. The range of $2 \theta$ was $0^{\circ}$ to $50^{\circ}$. The preliminary data of the powdered sample was calculated by indexing in the first $2 \theta$ strong intensity peaks using DASH 3.3.2 program [5].

\section{B. Computational analysis}

The molecular structure of 3NAOX are computed by performing both HF and B3LYP with basis set 6-311+G(d,p) in the ground state. Computational calculations for $3 \mathrm{NAOX}$ are performed using GAUSSIAN 09W [6] program package on i5 processor $/ 3.20 \mathrm{GHz}$ personal computer without any constraint on the geometry [7]. The first job was optimized geometry of title compound determined by computational work.

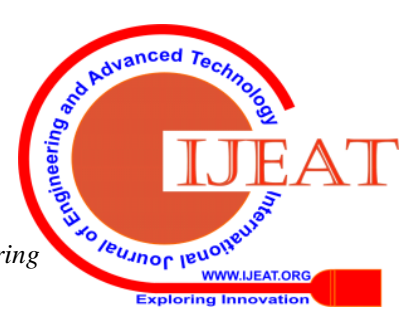


The HF and B3LYP method [8,9] combined with gradient-corrected correlational functional of Lee, Yang and Parr (LYP) [10]. Using principle of statistical mechanics, thermodynamic properties of 3NAOX have been calculated from normal mode of vibrational frequencies which provide the details about title compound in gas phase. GAUSSVIEW program [11] with symmetry considerations were used to assign vibrational frequencies. The electronic properties and energy value from FMOs analysis were calculated by the HF and B3LYP method.

\section{Spectral analysis}

FTIR and FT-Raman spectra of 3NAOX crystal were recorded in the range of 400 to $4000 \mathrm{~cm}^{-1}$ using Nexus 670 FTIR spectrometer and BRUKER RFS 27 FT-Raman Spectrometer, respectively. Nd:YAG laser at $1064 \mathrm{~nm}$ was used as source.

\section{Thermal analysis}

TG/DTA analyses of all the 3NAOX crystals were carried out by SII (SEIKO), Japan Analytical Instrument, and Model No: TG/DTA-6200 with $\mathrm{N}_{2}$ Atmosphere of range $20^{\circ} \mathrm{C} / \mathrm{Min}$. The samples used for this analysis were prepared by crushing the grown crystals.

\section{RESULTS AND DISCUSSION}

\section{A. Powder XRD Study}

The possible unit cell parameters for 3NAOX given in the Table 1. By comparing the powder XRD spectra and the predicted unit cell values in the salt formation is confirmed.

Table I:Unit cell parameters of 3NAOX

\begin{tabular}{|l|l|}
\hline $\begin{array}{l}\text { Unit cell } \\
\text { Parameters }\end{array}$ & 3NAOX \\
\hline $\mathrm{a}(\AA)$ & $21.929(2)$ \\
\hline $\mathrm{b}(\AA)$ & $9.083(9)$ \\
\hline $\mathrm{c}(\AA)$ & $13.943(1)$ \\
\hline$\alpha\left(^{\circ}\right)$ & 90 \\
\hline$\beta\left(^{\circ}\right)$ & 104.9 \\
\hline$\gamma\left({ }^{\circ}\right)$ & 90 \\
\hline Volume & 2682.7 \\
\hline
\end{tabular}

Powder XRD pattern of grown crystal 3NAOX compared with stimulated XRD pattern of 3-nitroaniline and oxalic acid was shown in Fig. 2. Some of the new intensity peaks are appear in 3NAOX crystals and some of the peaks are disappear were compared to 3-nitroaniline pattern. The possible unit cell parameters were identified and 3NAOX crystal belongs to monoclinic system was notable using DASH 3.3.2 program.

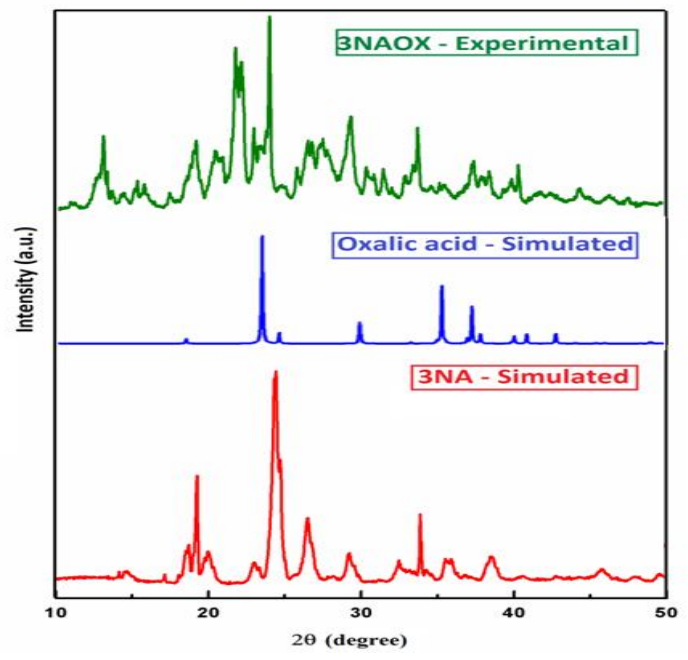

Fig. 2. Powder XRD pattern of 3NAOX

\section{B. Molecular geometry}

In 3NAOX, asymmetric part of unit cell contains 3-nitroaniline (cation) charge is neutralized with Hydrogen oxalate (anion). The optimized structure of 3-nitroanilinium hydrogen oxalate diagram and atom numbering scheme are shown in the Fig. 3 .

In phenyl ring, optimized bond length of $\mathrm{C}-\mathrm{C}$ is calculated as 1.389-1.401 $\AA$ in B3LYP level and 1.379-1.391 $\AA$ in HF level, which illustrates a good agreement with the experimental results. The values are obtained in the expected range with acceptable deviation which shows the effective optimization of the molecular structures, The $\mathrm{C}-\mathrm{O}$ bond lengths were calculated as 1.197-1.329 $\AA$ in B3LYP level and 1.184-1.306 $\AA$ in HF level in oxalate anion. These results are closed to the experimental values.
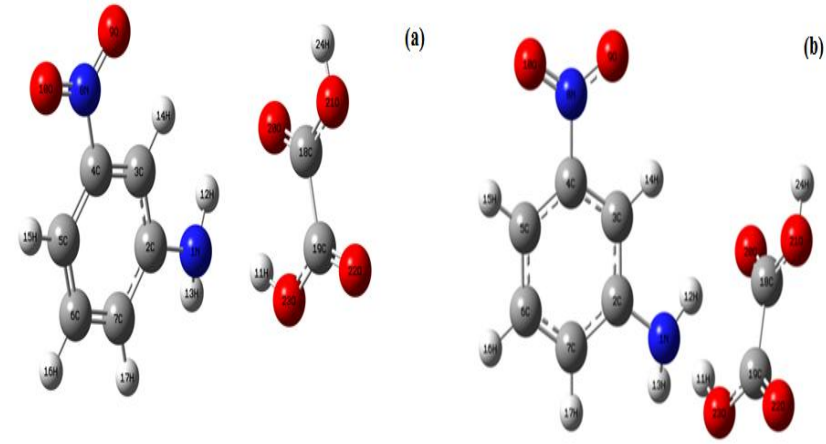

Fig.3. Optimized geometry of 3NAOX by (a) HF \& (b) DFT

\section{Mulliken atomic charge Analysis}

The histogram of atomic charges for 3NAOX is shown in Fig. 4. The hydrogen atom (H11) in oxalic acid group of 3NAOX is more electropositive (0.471e in $\mathrm{HF}$ and $0.461 e$ in $\mathrm{B} 3 \mathrm{LYP})$. Because, it attached with electronegative oxygen atom $(\mathrm{O} 23)$. Also, carbon atom has more electro negativity (C7) (-0.680e in $\mathrm{HF}$ and $-0.434 e$ in B3LYP). Because, it surrounded by two carbon atoms (C2 and $\mathrm{C} 6)$ (electronegative) and one hydrogen atom (H17).

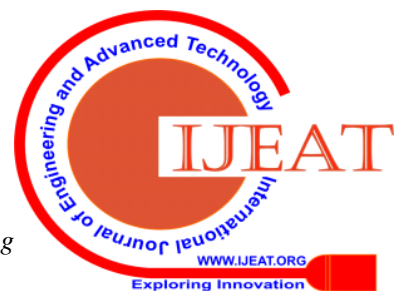




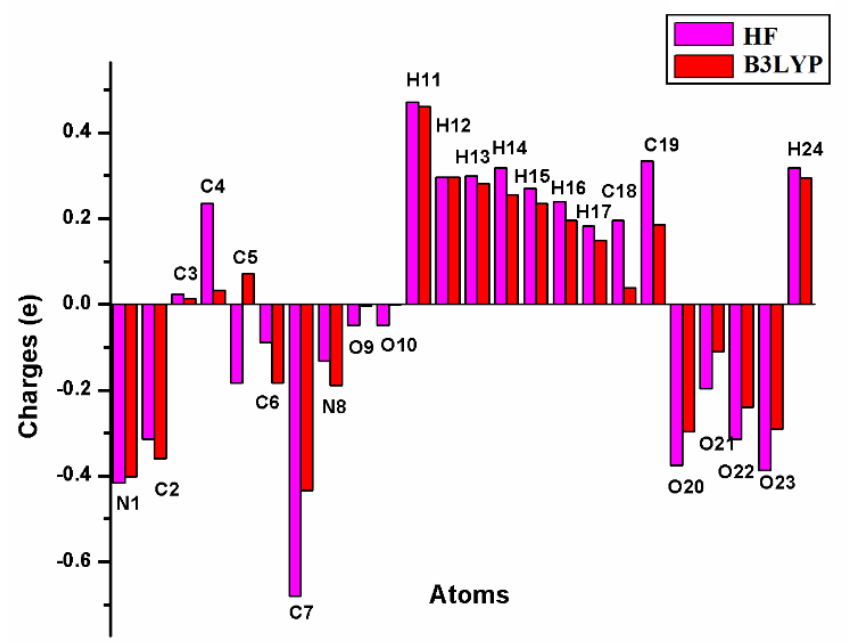

Fig.4. Histogram of atomic charges on 3NAOX by HF \&B3LYP methods

\section{Vibrational Analysis}

The 3NAOX consists of 24 atoms are undergoes 66 modes of vibrations. The experimental and computed IR and Raman spectra of 3NAOX are given in Fig. 5.

Vibrations of $-\mathrm{NH}_{2}$ group

The $\mathrm{NH}_{2}$ group vibrations are assigned as the asymmetric \& symmetric stretching, wagging, twisting, scissoring and rocking vibrations are spread over a region. In 3NAOX, the calculated wavenumber at $3894 \mathrm{~cm}^{-1}$ in $\mathrm{HF}$ and $3616 \mathrm{~cm}^{-1}$ in DFT(B3LYP) are assigned to $\mathrm{NH}_{2}$ antisymmetric stretching. $\mathrm{NH}_{2}$ symmetric stretching wavenumber are observed at 3852 and $3525 \mathrm{~cm}^{-1}$ in $\mathrm{HF}$ and DFTrespectively. $\mathrm{NH}_{2}$ scissoring vibrations in addition with out-plane bending $\mathrm{C}-\mathrm{H}$ vibrations scaled at 1835 in HF and $1666 \mathrm{~cm}^{-1}$ in DFT(B3LYP) level. Those vibrations peaks are absent in experimental spectra. $\mathrm{NH}_{2}$ twisting vibrations identified as a weak peak at $921 \mathrm{~cm}^{-1}$ in IR spectrum and scaled by HF and DFT(B3LYP) levels at 894 and $817 \mathrm{~cm}^{-1}$, respectively. The $\mathrm{NH}_{2}$ rocking vibrations are observed as a weak peak at 1347 in IR and $1359 \mathrm{~cm}^{-1}$ in Raman.

\section{Vibrations of $-\mathrm{NO}_{2}$ group}

The symmetric and asymmetric stretching vibrations of $\mathrm{NO}_{2}$ group are observed in the region around $1300-1370 \mathrm{~cm}^{-1}$ and 1500-1570 $\mathrm{cm}^{-1}$ for nitrobenzene and its substitutedcompounds. The $\mathrm{NO}_{2}$ asymmetric stretching vibrations are theoretically computed by $\mathrm{HF}$ and DFT(B3LYP) at 1770 and $1589 \mathrm{~cm}^{-1}$, respectively. The $\mathrm{NO}_{2}$ symmetric stretching vibrations are theoretically scaled at 1574 in $\mathrm{HF}$ and $1371 \mathrm{~cm}^{-1}$ in DFT(B3LYP).

\section{$C-N$ and $C-C$ vibrations}

The $\mathrm{C}-\mathrm{N}$ and $\mathrm{C}-\mathrm{C}$ stretching vibrations occurs in region around $1300-1600 \mathrm{~cm}^{-1}$ due to literature. The weak intensity peak at 1542 in IR spectrum is assigned to $\mathrm{C}-\mathrm{N}$ stretching vibrations and it is computed at 1574in $\mathrm{HF}$ and $1371 \mathrm{~cm}^{-1}$ in DFT(B3LYP) level. C $-\mathrm{C}$ stretching vibration scaled at 1835 and $1666 \mathrm{~cm}^{-1}$ in HF and DFT(B3LYP) level, respectively.

\section{C-Hvibrations}

These vibrations represent aromatic structure in $3 \mathrm{NAOX}$ and these vibrations are at around $3100 \mathrm{~cm}^{-1}$. Hence a shoulder peak at $3441,3338 \mathrm{~cm}^{-1}$ and a broad at $2901 \mathrm{~cm}^{-1}$ are obtained in IR spectrum is identified for $\mathrm{C}-\mathrm{H}$ stretching. The same stretching vibrations are theoretically by $\mathrm{HF}$ and DFTlevel at mode 62 , mode 61 , mode 60 and mode 59 in the range of $3402-3169 \mathrm{~cm}^{-1}$. The aromatic $\mathrm{C}-\mathrm{H}$ out-plane bending and in-plane bending vibrations are representing the band around of $900-1100 \mathrm{~cm}^{-1}$ and $1100-1300 \mathrm{~cm}^{-1}$, respectively. For the title compound $\mathrm{C}-\mathrm{H}$ in-plane bending vibration observed as a weak peak at $1623 \mathrm{~cm}^{-1}$ in IR spectrum and calculated at 1626 $\mathrm{cm}^{-1}$ in $\mathrm{HF}$ and $1490 \mathrm{~cm}^{-1}$ in DFT(B3LYP) level, respectively. A weak peak presented at $1093 \mathrm{~cm}^{-1}$ in IR spectrum for $\mathrm{C}-\mathrm{H}$ out-plane bending vibration and its calculated at $1082 \mathrm{~cm}^{-1}$ in $\mathrm{HF}$ and $995 \mathrm{~cm}^{-1}$ in DFT(B3LYP) level.

Vibrations of carboxylic anion

The carboxylic $(\mathrm{COOH})$ group and $\mathrm{COO}^{-}$group usually expected in $1755 \mathrm{~cm}^{-1}$. In 3NAOX crystal, it is computed in the range 2063-1789 $\mathrm{cm}^{-1}$ in the HF and DFT(B3LYP) level. The $\mathrm{OH}$ stretching mode of the carboxylic group is computed in range 3263-4103 $\mathrm{cm}^{-1}$ in the $\mathrm{HF}$ and DFTlevel. But corresponding peak are absent in experimental spectra. The scissoring vibrations of carboxylic group is found as a weak peak at $1013 \mathrm{~cm}^{-1}$ in Raman spectrum, it is calculated at 1029 and $941 \mathrm{~cm}^{-1}$ in the HF and DFT(B3LYP) level, respectively. The rocking vibrations of carboxylic group is computed at 263 and $246 \mathrm{~cm}^{-1}$ in the HF and DFT(B3LYP) level, respectively.
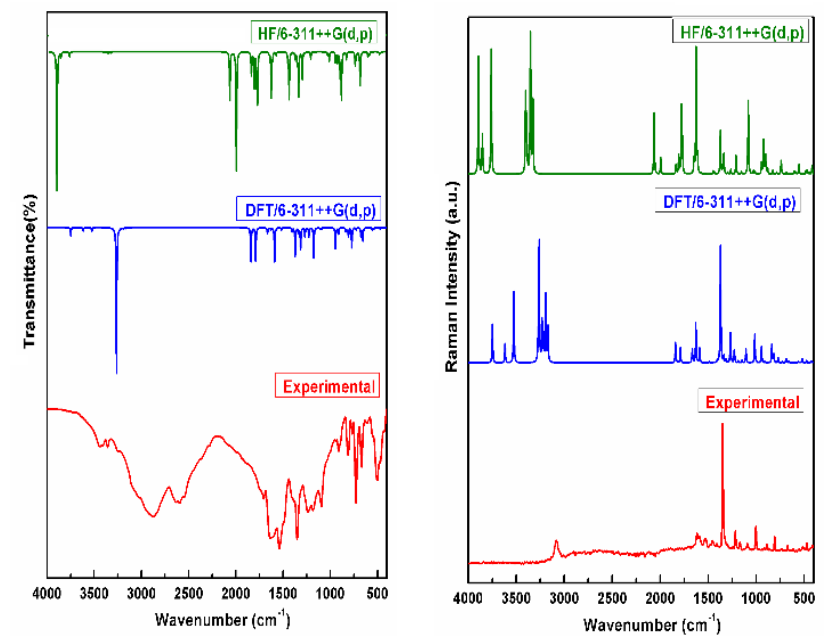

Fig. 5. Experimental and computed IR \& Raman spectra of 3NANO

\section{E. Frontier Molecular Orbital Analysis}

In the organic molecules, optical and electric properties proposed by using frontier molecular orbital analysis [12]. In molecular orbital have two important interactions; such as HOMO represents the ability to donate an electron and another one is LUMO describe electron acceptor. Also, these orbitals are named as frontier orbitals. FMO analysis [13] is used to identify the highly reactive position in $\pi$-electron systems and it also explains several types of reaction in conjugated system. Also, FMO plays an essential part in abiding chemical stability of the compound [14-16].

The calculated HOMO and LUMO energies and some important parameters of the $3 \mathrm{NAOX}$ were calculated by HF and DFT/B3LYP method as shown in the Table 2.

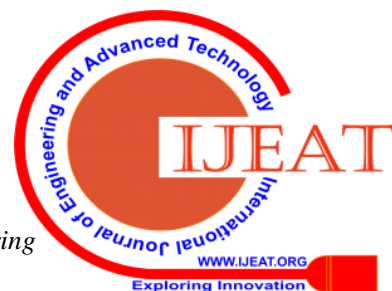


The corresponding energy level diagrams of the present molecules are shown in Fig. 6. A huge amount of charge transfer occurred in $3 \mathrm{NAOX}$ is indicated by small energy gap, which is connected with a high chemical reactivity. The small value of energy gap and high value of charge transfer leads the molecules to biologically active. For 3NAOX, 407 energy values are obtained in the range of $-20.649-+51.775$ au and -19.215- +50.032 au in HF and DFT(B3LYP) method, respectively. The computed HOMO and LUMO energy values are $-0.344 / 0.028$ au in $\mathrm{HF}$ and $-0.264 /-0.111$ au DFT(B3LYP) method and energy gap was 0.372 a.u in HF and 0.153 a.u in DFT(B3LYP) method.

Table II:Molecular orbital values of 3NAOX

\begin{tabular}{|l|l|l|}
\hline Parameters (a.u.) & $\begin{array}{l}\mathrm{HF} / \\
6-311++\mathrm{G}(\mathrm{d}, \mathrm{p})\end{array}$ & $\begin{array}{l}\text { B3LYP/ } \\
6-311++\mathrm{G}(\mathrm{d}, \mathrm{p})\end{array}$ \\
\hline $\mathrm{E}_{\mathrm{LUMO}}$ & 0.028 & -0.111 \\
\hline $\mathrm{E}_{\mathrm{HOMO}}$ & -0.344 & -0.264 \\
\hline$\Delta\left(\mathrm{E}_{\mathrm{LUMO}}-\mathrm{E}_{\mathrm{HOMO}}\right)$ & 0.372 & 0.153 \\
\hline Electrophilicity index & 0.067 & 0.230 \\
\hline Ionization potential $(\mathrm{I})$ & 0.344 & 0.264 \\
\hline Chemical hardness $(\eta)$ & 0.186 & 0.077 \\
\hline Electronegativity $(\chi)$ & 0.158 & 0.188 \\
\hline Electron affinity $(\mathrm{A})$ & -0.028 & 0.111 \\
\hline Chemical potential $(\mu)$ & -0.158 & -0.188 \\
\hline
\end{tabular}

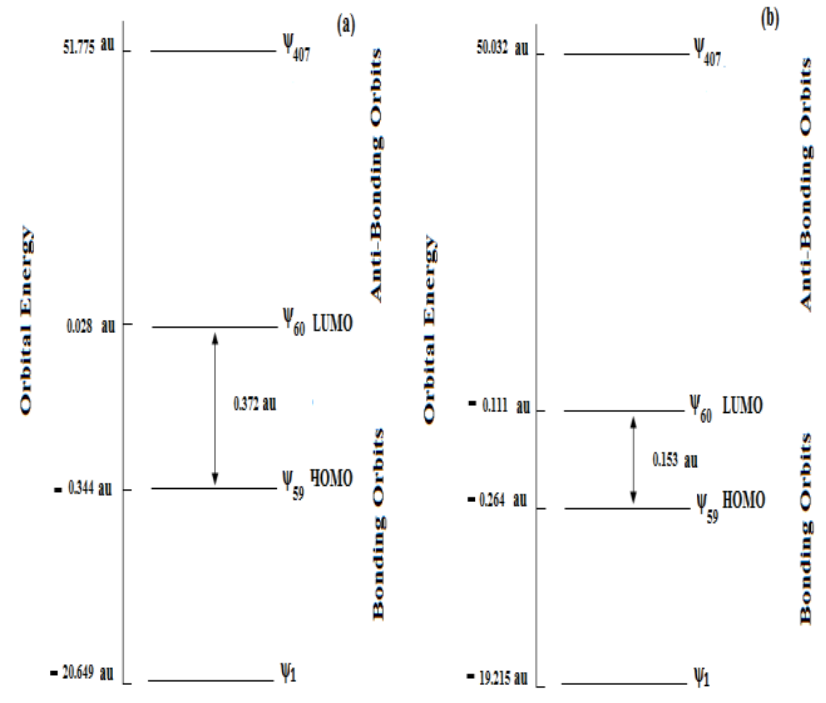

Fig. 6.Molecular orbital energy level diagram of 3NAOX by (a) HF and (b) DFT(B3LYP) method

\section{F. Thermal Analysis}

3NAOX thermal behaviour was analyzed by using simultaneous DTA/TGA analysis in the temperature range $40-750^{\circ} \mathrm{C}$ in air atmosphere. The TGA/DTA curves of 3 NAOX were given in the Fig. 7. The TGA/DTA curve represent that the decomposition in the range of $157.5-750^{\circ} \mathrm{C}$. The three main stages decomposition of 3NAOX occurred within temperature range as given Fig. 7. In TGA/DTA curve, weight loss $9.7 \%$ noted in temperature range $150-180^{\circ} \mathrm{C}$ due to the elimination of water group from $3 \mathrm{NAOX}$ it indicates first stage of decomposition. The second stage of major weight loss $(31 \%)$ occurs at $180-220^{\circ} \mathrm{C}$ temperature range, which is due to the liberation of $\mathrm{CO}_{2}$. The next decomposition stage is owing to the removal of $\mathrm{NO}$ and $\mathrm{CO}$ in the temperature range $220-280^{\circ} \mathrm{C}$ with weight loss of $29 \%$. The loss of water molecule in lattice is identified as two weak endothermic peaks at $81.9^{\circ} \mathrm{C}$ and $108.7^{\circ} \mathrm{C}$ and another endothermic peak identified at $157.5^{\circ} \mathrm{C}$ is may be the melting point of $3 \mathrm{NAOX}$. The decomposition of the organic compound is noted as exothermic peak at $448.1{ }^{\circ} \mathrm{C}$.

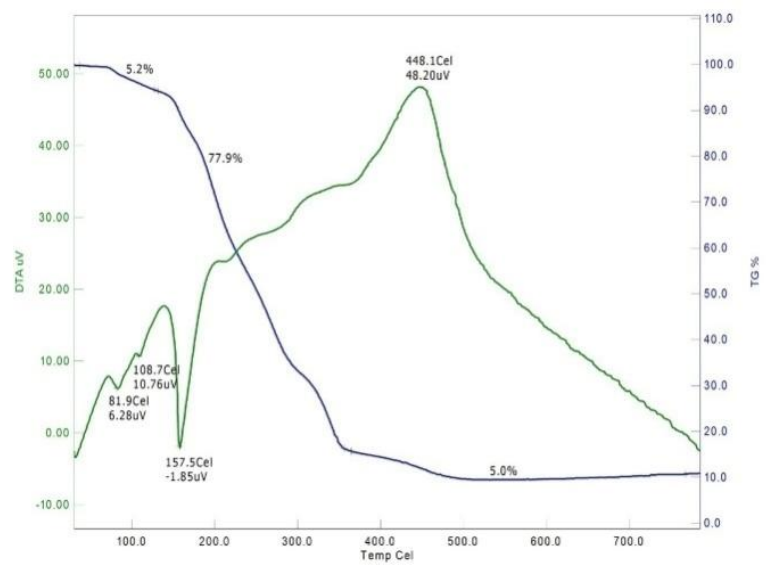

Fig.7. TGA/DTA curve of 3NAOX

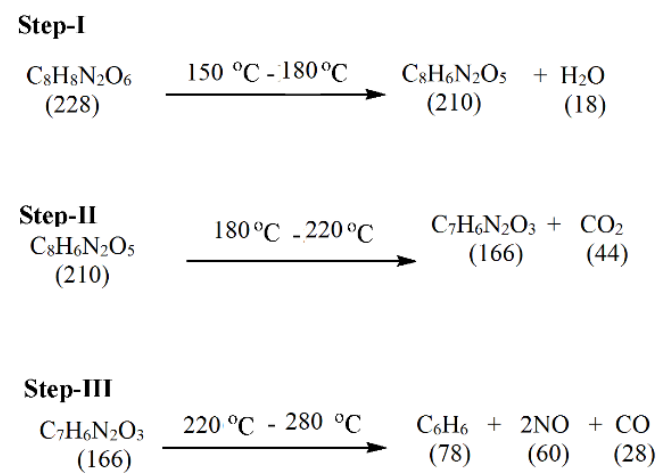

Note: The values given in parenthesis stand for the molecular weights of the respective species.

Fig. 8. Decomposition steps of 3NAOX

\section{G. Antimicrobial Activity Analysis}

3NAOX crystal was tested against Candida Albicans (C.albicans) to analyze the antifungal activity by disc diffusion method.The above mentioned bacterial species were prepared at $50 \mathrm{mgmL}^{-1}$ and $100 \mathrm{mgmL}^{-1}$ concentrations. The measured diameter zone of inhibition of these microorganisms is shown in Table 3. From the Table III, it was clear that 3-nitroanilinium hydrogen oxalate complex was moderately active against the organisms. 
Table III: Antifungal activity of 3NAOX compound against some human pathogens

\begin{tabular}{|c|c|l|}
\hline \multirow{2}{*}{ Sample } & \multirow{2}{*}{$\begin{array}{l}\text { Concentration } \\
(\mathrm{mg} / \mathrm{mL})\end{array}$} & $\begin{array}{l}\text { Zone Of Inhibition in } \\
\text { diameter }(\mathrm{mm})\end{array}$ \\
\cline { 2 - 3 } & & $\begin{array}{l}\text { C. Albicans } \\
\text { (Used Micro organisms) }\end{array}$ \\
\hline \multirow{2}{*}{ 3NANO } & 50 & 12 \\
\cline { 2 - 3 } & 100 & 12 \\
\hline SD & $50 / 100$ & 16 \\
\hline
\end{tabular}

SD-Standard drug (Antifungal activity)-Ketokonazole

\section{CONCLUSION}

3-nitroanilinium hydrogen oxalate has been synthesized and characterized by various methods. The detailed interpretation of the calculated IR and Raman spectra at HF and B3LYP 6-311G++(d,p) level of theory with the experimental results shows the reliability of $3 \mathrm{NAOX}$ molecule. The higher stability of the title molecule is confirmed from the computed HOMO-LUMO energy gap. Thermal stability and antimicrobial activity of the title compound has been calculated.

\section{REFERENCES}

1. C. C.Teng, and A. F. Garito, "Dispersion of the nonlinear second-order optical susceptibility of organic systems," Physical Review., vol. B 28, Aug. 1983, pp. 6733-6766

2. D. M. Bishop, B. Champagne and B. Kirtman, "Relationship between static vibrational and electronic hyperpolarizabilities of $\pi$-conjugated push-pull molecules within the two-state valence-bond charge-transfer model," J.Chem. Phys., vol. 109, Nov. 1998, pp. 9987-9994

3. H. Reis, M. G. Papadopoulos, P. Calaminici, K. Jug and A. M. K Ö "Calculation of macroscopic linear and nonlinear optical susceptibilities for the naphthalene, anthracene and meta-nitroaniline crystals", Chem. Phys., vol. 261, Nov. 2000, pp.359-371

4. A. K. Jain, S.C. Mehta and N. M. Shrivastava, "Hypoglycemic and antihyperglycemic effects of newly synthesized sulfonyloxy derivatives of azalactone in normal and alloxan diabetic rabbits", Indi. $J$. Pharmaco., vol. 37(6), pp.395-396

5. W.I.F. David, K. Shankland and J. Van de streek, E. Pidcock, W.D.S Motherwell and J.C. Cole, "DASH: a program for crystal structure determination from powder diffraction data", J. Appl. Cryst., vol. 39(6), 2006, pp.910-915

6. M.J. Frisch, G.W. Trucks, H.B. Schlegel, G.E. Scuseria, M.A. Robb et al, Gaussian 09, Revision A.1, Gaussian, Inc., Wallingford CT, 2013

7. H.B. Schlegel, "Optimization of equilibrium geometries and transition structures”, J. Comput. Chem., vol. 3(2), Sep. 1982, pp.214-218

8. P. Hohenberg and W. Kohn, "Density Functional Theory (DFT)", Phys. Rev. B., vol. 136, 1964, 864-871,

9. A.D. Becke, "Density-functional thermochemistry. I. The effect of the exchange-only gradient correction", J. Chem. Phys., vol. 96(3), Oct. 1993, pp.2155-2160.

10. C. Lee, W. Yang and R.G. Parr, "Phys. Rev., B37, 785-789, (1988).

11. A. Frisch, A.B. Nielson, and A.J. Holder, GAUSSVIEW User Manual, Gaussian Inc., Pittusburgh, PA, 2000

12. Jean, Yves, Volatron, François. An Introduction to Molecular Orbitals. Oxford University Press. 11.03, 2005

13. Palafox M.A., Int. J. Quant. Chem. 77 (2000) 661-684.

14. Fleming I, Frontier Orbitals and Organic Chemical Reactions, John Wiley \& Sons, New York, 1976.

15. V. Siva, S. Suresh Kumar, M. Suresh, M. Raja, S. Athimoolam, S. Asath Bahadur, $\mathrm{N}-\mathrm{H} \cdots \mathrm{O}$ hydrogen bonded novel nonlinear optical semiorganic crystal (4-methoxyanilinium trifluoroacetate) studied through theoretical and experimental methods, J. Mol. Struct. 1133, 2017, pp. 163-171

16. S. Thangarasu, V. Siva, S. Athimoolam, S. Asath Bahadur, Molecular structure, spectroscopic and quantum chemical studies on benzoic acid and succinic acid co-crystals of 2-Aminopyrimidine, J Theo. Comp. Chem., 174, 2018,pp.1850021.

\section{AUTHORS PROFILE}

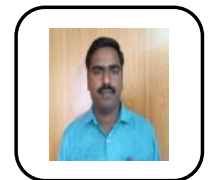

Dr. S. Thangarasu is a Assistant Professor in the Department of Physics, School of Advanced Sciences at Kalasalingam Academy of Research and Education, India. He has obtained Ph.D in Physics from Kalasalingam Academy of Research and Education in 2017 and also received his B.Sc. \& M.Sc. Degree in Physics from Manonmaniam Sundaranar University in the years 2005 and 2007 , respectively. He has expertise in the areas of Crystal growth and Computational Physics. He has published seven papers in international/national journals in addition to extensive presentations in conferences.

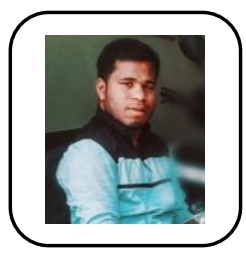

Dr. V. Siva obtained Ph.D in Physics from Kalasalingam Academy of Research and Education in 2018. He has received his Bachelor's Degree and Master's Degree in Physics from Government Arts College (Autonomous), Coimbatore, which is affiliated to Bharathiar University in the years 2010 and 2012, respectively. He has expertise in the areas of Crystallography, Crystal growth and Computational Physics. To his credit, he has published more than 20 articles in journals of international repute besides ten more as proceedings. Further, he has presented papers in various conferences and seminars. His current research interest is development of Metal-Organic Frameworks (MOFs) for sensor and energy storage application.

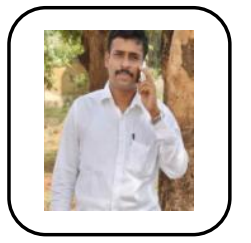

Dr. Shunmuganarayanan Athimoolam, Head of the Department in Physics at University College of Engineering Nagercoil, Anna University Constituent College, India. He has received his Doctoral degree in the area of X-ray Crystallography from Madurai Kamaraj University in the year 2008. He joined as Assistant Professor of Physics at University College of Engineering Nagercoil from the year 2009. His current research interests are Crystal and molecular structure analyses, hydrogen bonding analyses, Coordination and inclusion compounds, IR and Raman spectral analyses, DFT related theoretical studies, nano-drug synthesis and characterization, etc. He has published more than 150 papers in international/national journals in addition to extensive presentations in conferences.

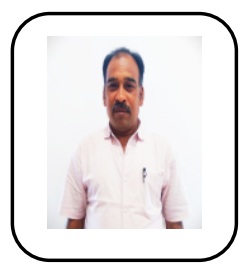

Dr. S. Asath Bahadur is a Senior Professor in the Department of Physics, School of Advanced Sciences at Kalasalingam Academy of Research and Education, India. He has obtained Ph.D. in the area of X-ray crystallography from Madurai Kamaraj University in 1994 and also received his M.Phil. and M.Sc. Degree in physics from Madurai Kamaraj University.He has expertise in the areas of Crystallography and Material science. $\mathrm{He}$ has published more than eighty-fivepeer-review research articles in journals of international repute besides seventy more as proceedings. 